ВАК 05.02.07

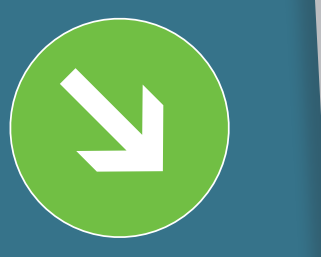

Ключевые слова: станкостроение, комплектующие изделия, технологическая независимость, импортонезависимость, конкурентоспособность

\title{
ПРОИЗВОДСТВО КРИТИЧЕСКИ ВАЖНЫХ КОМПЛЕКТУЮЩИХ ДЛЯ РОССИЙСКОГО СТАНКОСТРОЕНИЯ
}

\section{Алексей ПЕСКОВ, Виктор ИВАХОВ, НиколаЙ ЮДЕНКОВ}

\begin{abstract}
Сформулированы предложения по созданию в России производств различных групп комплектующих изделий для станкостроения, обеспечивающих технологическую независимость государства и независимость от импортных поставок. Для различных групп комплектующих рассмотрены соответствующие организационные подходы: государственное финансирование, частно-государственное партнерство, СПИК, совместные предприятия и пр.
\end{abstract}

Российское станкостроение оказалось одним из первых в 2014 году в санкционном списке западных стран (АО «РТ-Станкоинструмент»), в связи с известными событиями на Украине, причем в одном списке с оборонными предприятиями РФ.

Почему станкостроителям была оказана такая большая честь - быть в первых рядах под санкциями, которые выражаются в следующем: запрещен импорт и экспорт оружия, а также поставки продукции «двойного назначения» и высоких технологий, которые могут быть использованы в оборонной промышленности. Станкостроение - это отрасль высочайших технологий, обеспечивающая «технологическую независимость» и обороноспособность государства.

Вот почему оно особенно в чести у высокоразвитых стран: Китая, Германии, Японии, США, Франции, Италии, Индии и еще почти 20 (Тайвань, Южная Корея, Швейцария, Чехия и др.) более мелких, но высокоразвитых стран, которые в списке производителей станков опережают нашу страну. Видимо на Западе не поняли, что у нас почти не осталось станкостроения, которое было в СССР, и ввели санкции.

А станкостроение СССР было одним из лидеров по производству станков, их технологическому уровню и производительности. СССР по производ- ству станков всегда занимал 2-3 место, а по потреблению - 1-2 место в мире, обеспечивая, прежде всего, оборонную промышленность, совершенно уникальными технологиями. В стране бытует мнение, что мы много станков импортировали, но статистика говорит об обратном. По статистике (последняя перепись станков была проведена уже в России, в 1992 году) [1], доля импортных станков и кузнечнопрессовых машин в структуре парка страны составляла 7,5\%. Надо учитывать, что больша́я часть станков была ввезена в СССР по репарациям после ВОВ, кроме того, доля станков, приобретенных в странах СЭВ, в основном в Чехословакии, Венгрии, ГДР, Болгарии, Польше, превосходила долю станков, приобретенных в западных странах. Эти станки продолжали и продолжают во многих случаях работать и сегодня. Нынешний уровень производства станков и кузнечнопрессовых машин составляет примерно $2-2,5 \%$ от уровня производства в СССР.

Если кому-то неизвестно, то санкции против советского станкостроения были введены почти сразу после войны - после Фултонской речи Уинстона Черчилля (1946 г.) и после образования НАТО. В дальнейшем были КОКОМ и поправка Джексона - Вэника, Вассенаарские соглашения. Таким образом, мы никогда не могли опираться на передовые западные технологии. Эти санкции не меша- 
ли, а может быть, и способствовали созданию собственных уникальных технологий.

Надо сказать, что собственное производство металлорежущих станков и КПМ достигло в 1980 году 257 тыс. [2].

Особенностью отечественного станкостроения была опора на собственные силы в научном обеспечении, проектировании и производстве станков и КПМ, производстве всех необходимых комплектующих изделий.

Страна производила высокоточные станки, высокопроизводительные станки с ЧПУ, автоматические линии и линии безлюдных производств с ЧПУ, уникальные (самые крупные в мире) станки и КПМ, роботов и многое другое технологическое оборудование. СССР строил в странах СЭВ заводы по производству станков и комплектующих изделий (например, завод по производству электромагнитных муфт в г. Остшешув, два завода по производству патронов и зажимных устройств для станков в г. Белосток (Польша); станкостроительный завод в г. Шиньян (КНР); производство токарных и фрезерных станков, станкостроительный завод № 1 в г. Хо Ши Мин (Вьетнам); станкостроительный завод по производству токарных станков (КНДР); производство транспортеров стружки для станков в г. Бургас, узлы и системы управления для роботов в г. Стара Загора (Болгария) и др.). Конструирование и научное сопровождение комплектующих изделий в странах СЭВ обеспечивали советские НИИ.

Сегодня сложилась катастрофическая обстановка в отрасли, где должны создаваться новейшие технологии производства, в том числе для производства продукции военного назначения. К сожалению, в течение 30 последних лет (с нелегкой руки Е.Т. Гайдара и Е.Г.Ясина, объявивших, что нам не нужно станкостроение и станки мы будем покупать за рубежом) станкостроение практически лишилось государственного финансирования. В дальнейшем, либеральное правительство России придерживалось псевдорыночной теории, полагая, что рынок сам все решит. Совершенно необоснованно делалась ставка на иностранные инвестиции, которых не было и не будет. Никто не продаст нам лицензии на новые технологии, не станет финансировать отрасль, которая, кроме конкуренции, может создавать технологии для военно-промышленного комплекса. К сегодняшнему дню отрасль практически разрушена. Практически исчезло производство специальных комплектующих изделий для станков.

Ассоциация «Станкоинструмент» предлагает воссоздать в стране станкостроение по образцу высокоразвитых стран с использованием огромного опыта СССР.
Главная цель - обеспечение технологической независимости России и конкурентоспособности отечественного станкостроения.

Для достижения поставленной цели необходимо решить следующие задачи:

$\rightarrow$ обеспечить станкостроение финансовыми ресурсами в необходимых объемах;

$\rightarrow$ обеспечить возрождение отраслевых научноисследовательских институтов для станкостроения;

$\rightarrow$ создать мощные КБ при заводах для проведения НИОКР;

$\rightarrow$ восстановить подготовку в вузах и специальных училищах инженеров для работы в отрасли;

$\rightarrow$ освоить критические виды комплектующих в России и довести их технические параметры до уровня лучших мировых образцов станкоинструментальной продукции;

$\rightarrow$ построить новые заводы по производству станков, КПМ и комплектующих изделий к ним, в том числе обеспечить станкостроительное производство достаточным количеством термоконстантных цехов.

В Ассоциации «Станкоинструмент» совместно с предприятиями отрасли и отраслевыми НИИ был создан перечень комплектующих изделий, необходимый для производства станков. Надо сказать, что сегодня большинство комплектующих изделий импортируется, что при жестком подходе не дает оснований для признания собранных из них станков отечественного производства. Электрооборудование, в том числе электронное, почти полностью комплектуется импортными элементами. Очень велика доля импортных комплектующих в изготовлении станков и КПМ, при этом по многим критическим комплектующим существует запрет на экспорт в Россию.

Ассоциация провела анализ возможностей возрождения производств комплектующих изделий, в том числе в сотрудничестве с западными компаниями, и разработала перечень предложений по освоению их выпуска в России. В этот список вошло более сотни различных комплектующих для производства станочного оборудования.

Все комплектующие изделия сгруппированы в шесть блоков.

Комплектующие различных групп требуют специфических условий производства, поэтому производство современных станков и станочных систем очень наукоемкое, низкорентабельное и требует государственных субсидий, существенного снижения налогов, вплоть до полной их отмены, и других льгот. Такой подход принят во всех развитых странах с мощным станкостроением. 
КОМПЛЕКТУЮЩИЕ ИЗДЕЛИЯ, ДЛЯ

ПРОИЗВОДСТВА КОТОРЫХ ТРЕБУЕТСЯ СТРОИТЕЛЬСТВО НОВОГО ПРЕДПРИЯТИЯ ЗА СЧЕТ 100\%-НЫХ ГОСУДАРСТВЕННЫХ ИЛИ ЧАСТНЫХ ИНВЕСТИЦИЙ

В России необходимо построить завод для производства направляющих качения (шариковых, роликовых). В качестве примера ниже приводятся

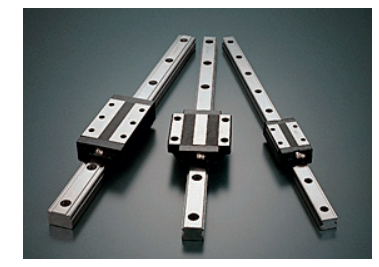
направляющие станков.

Эти направляющие применяются на большинстве (80-90\%) станков с ЧПУ. Производство таких направляющих является очень сложной технологической проблемой, и круг фирм, которые в состоянии производить такие направляющие, очень узок. Сегодня Россия закупает эти направляющие в Японии и Германии. В СССР такие направляющие производились, хотя их качество уступало импортным. Такие направляющие являются «критическими» - от них зависит точность и долговечность станков, прекращение их импорта может привести к серьезным последствиям. Наиболее известные фирмы, которые производят лучшие линейные направляющие в мире - это ТНК (Япония) и Schneeberger (Германия, Швейцария). СССР одно время производил направляющие качения по лицензии фирмы ТНК, но в дальнейшем производство было разрушено, необходимо вновь работать с иностранными производителями с целью восстановления производства. При строительстве предприятия необходимо учитывать, что направляющие станков относятся к сверхточной продукции и их изготовление требует термоконстантных условий, качественной термообработки, высокоточного металлообрабатывающего оборудования, а также высококлассной измерительной техники.

КОМПЛЕКТУЮЩИЕ ИЗДЕЛИЯ, ДЛЯ

ПРОИЗВОДСТВА КОТОРЫХ НЕОБХОДИМО ПРИВЛЕЧЕНИЕ ПРЕДПРИЯТИЙ ОПК В РАМКАХ ПРОГРАММЫ «КОНВЕРСИЯ»

Практика освоения комплектующих изделий по конверсии на предприятиях оборонно-промышленного комплекса упирается в одну проблему - высокие накладные расходы, которые ведут к завышенному ценообразованию и неконкурентоспособности данных видов комплектующих на рынке.
Прежде всего необходимо создать производство современных отечественных компонентов для систем ЧПУ и других систем управления для м/о станков. Важнейшим узлом станков и систем из станков является УЧПУ (устройство числового программного управления). В России производством ЧПУ занимается более десяти фирм, их продукция частично может применяться в современных станках нормального класса точности, а также при ремонте и модернизации станков.

К сожалению, в России отсутствуют системы ЧПУ высокого класса и системы для суперточных станков. Отсутствуют и годные для производства разработки. Неоднократно отечественные системы высокого уровня на отечественных процессорах брался разработать и даже производить МГТУ «СТАНКИН», но деньги расходовались, а системы так и не были созданы. За эталон можно принять системы ЧПУ компаний Mazak и Fanuk (Япония), Heidenhain и Siemens (Германия). Японские компании сотрудничать для создания совместных производств не готовы, поскольку опасаются санкций США, a Siemens отказался организовывать совместное производство в России до тех пор, пока потребность не возрастет до 10 тыс. систем в год.

Разумеется, привлечение иностранных партнеров для создания совместных предприятий не должно ограничиваться системами ЧПУ, при внедрении систем ЧПУ необходимо организовывать массу других производств.

Цифровизация отрасли должна обеспечиваться современными разработками. В их перечень входит программное обеспечение систем ЧПУ (на базе промышленных компьютеров с двух- и многоядерными процессорами) для станков всех типов с цифровым управлением приводами и электроавтоматикой (что подразумевает до 11 и более управляемых одновременно осей высокого быстродействия, параллельную обработку информации, встраивание в информационные системы предприятий, работу через Интернет, самодиагностику станка, сервисные функции, что обеспечивает взаимодействие систем в оборудовании согласно требованиям «Индустрии 4.0»).

Также в перечень входит программное обеспечение CAD/CAM систем для отечественных систем ЧПУ и других систем управления м/о станков, программное обеспечение мониторинга промышленного оборудования согласно требованиям «Индустрии 4.0».

Покупка станков в развитых странах несет серьезную опасность, поскольку некоторые фирмы ставят в системы ЧПУ микросхемы с «жучками». Эти «жучки» выполняют функции передатчика информации производителю станка: его GPS-местоположение, 

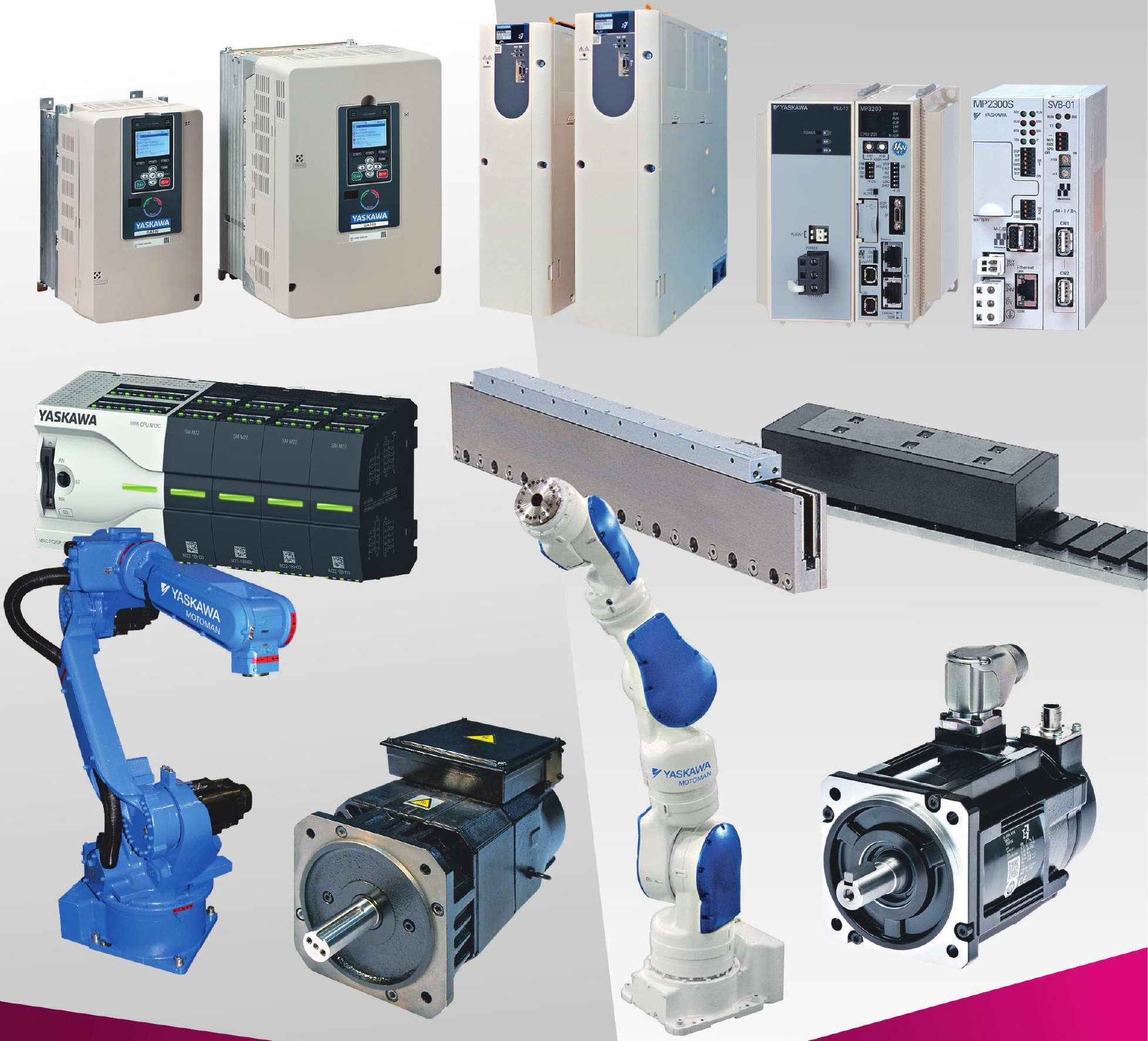
- Преобразователи частоты от 0,4 до 12000 кВт
- Шпиндельные двигатели
- Комплектные сервоприводы от 0,003 до 75 кВт
- Линейные сервосистемы
- Контроллеры управления движения
- Программируемые логические контроллеры
- Роботы

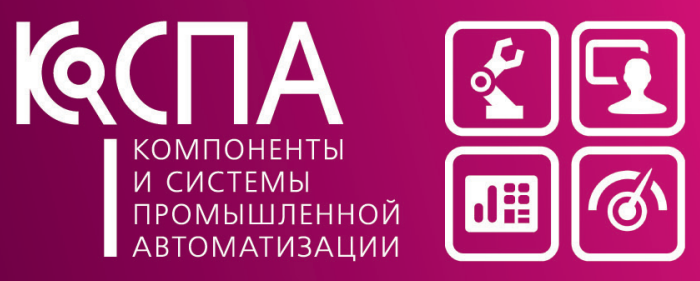

+7 (495) 660-28-22; www.cospa.ru

ООО «КОСПА»ОФИЦИАЛЬНЫЙ ПАРТНЕР И СЕРВИСНЫЙ ЦЕНТР YАSКАWA 
что он производит, технологию производства, количество изделий, программу (чертеж) изготовления детали и т.п. В критической ситуации станок может быть выведен из строя. Заказ оборудования уже является демаскирующим фактором. Поэтому в СССР С.П.Королёв категорически запретил на заводах Роскосмоса использовать импортные станки.

\section{КОМПЛЕКТУЮЩИЕ ИЗДЕЛИЯ, ДЛЯ СЕРИЙНОГО ПРОИЗВОДСТВА КОТОРЫХ В РОССИИ НЕОБХОДИМО ПРИВЛЕЧЕНИЕ ЗАРУБЕЖНЫХ ПАРТНЕРОВ И ИНВЕСТОРОВ}

К видам продукции, без которой производство станков невозможно, относятся и шариковые винтовые передачи (ШВП).

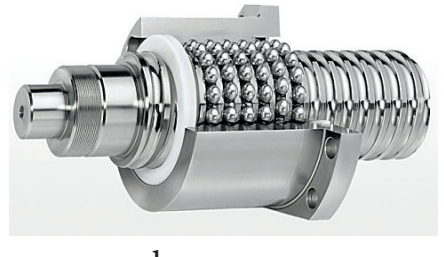
Зачастую ШВП производят фирмы, которые изготавливают подшипники.

Шариковые и роликовые винтовые передачи, которые в СССР производились прежде всего станкостроительными заводами: «Микрон» (г. Одесса) и «РСЗ» (г. Рязань). Были и другие предприятия, которые производили ШВП в основном для собственного потребления или других отраслей промышленности (например, для шасси самолетов). Сегодня в России есть производство ШВП, которые непригодны для станков, так как имеют малую точность. Для станков необходимы специальные ШВП высокой точности, высокой жесткости и высокой быстроходности. Ведущие мировые производители, кроме общеизвестных типов винтов, делают шариковые винты с двухсторонней заделкой, винты с внутренним жидкостным охлаждением, специальные ШВП картриджи. Наиболее известные производители ШВП в мире - SKF (Швеция), ТНK (Япония), KSK (Чехия). Эти три компании могут быть потенциальными партнерами при создании производства современных шариковых винтовых передач.

Для привлечения иностранных инвесторов необходимо создание условий, обеспечивающих уверенность и безопасность бизнеса, создание экономических стимулов для развития производства комплектующих - налоговые льготы и обеспечение государственными заказами на начальном этапе. Для организации производства комплектующих изделий необходимо использовать механизмы СПИК и создания совместных производств. На предприятиях, созданных с зарубежными партнерами и инвесторами, необходимо производить продукцию, которую на начальном этапе нам сложно изготавливать на высоком уровне из-за отсутствия НИИ, обеспечивающих научное сопровождение и развитие отечественных комплектующих изделий.
КОМПЛЕКТУЮЩИЕ ИЗДЕЛИЯ, ПРОИЗВОДСТВО КОТОРЫХ В РОССИИ ОСВОЕНО, НО ТРЕБУЕТСЯ ПРИНЯТИЕ ДОПОЛНИТЕЛЬНЫХ МЕР ДЛЯ ДОВЕДЕНИЯ ТЕХНИЧЕСКИХ ПАРАМЕТРОВ ДО СООТВЕТСТВИЯ МИРОВОМУ УРОВНЮ

До сих пор существует ряд предприятий, которые еще во времена СССР обеспечивали запросы станкостроителей, но, по большей части, для производимых ими комплектующих необходимы усовершенствова-

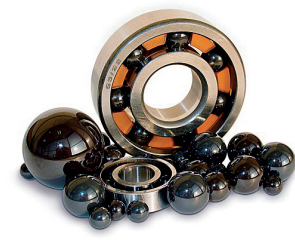
ния в соответствии с новыми требованиями. К изделиям этой группы относятся: высокоточные подшипники для станков, высокоскоростные прецизионные подшипники с керамическими шариками для шпиндельных узлов (дуплексы, триплексы, картриджи и т.п.), в том числе с высокими скоростными характеристиками (Dmn> 5000 000), а также эко-подшипники, системы автоматического регулирования натяга в подшипниках шпиндельных узлов. Такие подшипники ранее производились на Саратовском ГПЗ. К сожалению, теперь такого производства нет, а ведь этот завод выпускал точные подшипники, подобные продукции компаний SKF (Швеция), SNFA (Италия), TIMKEN (СШA), FAG (Германия), NTN (Япония).

Сегодня подшипники для станков изготавливает Вологодский подшипниковый завод. Этот завод пока освоил производство не очень широкой номенклатуры подшипников класса точности не выше 4. При государственной поддержке этот завод мог бы освоить более современные подшипники и узлы, в том числе с керамическими шариками, дуплексы и триплексы, эко-подшипники, подшипники более высокой точности, расширить номенклатуру, производить подшипниковые картриджи и т.п. Этот вопрос очень важно решать немедленно, так как России запрещено продавать подшипники классов более четвертого. Это существенно ограничивает возможности производства станков, а точные станки просто невозможно произвести без подшипников классов 1 и 2.

\section{КОМПЛЕКТУЮЩИЕ ИЗДЕЛИЯ ДЛЯ \\ МЕТАЛЛОРЕЖУЩЕГО ОБОРУДОВАНИЯ, КОТОРЫЕ НЕОБХОДИМО САМОСТОЯТЕЛЬНО ОСВАИВАТЬ И ПРОИЗВОДИТЬ В РОССИИ}

Очень болезненным является вопрос производства шпиндельных узлов. Вопервых, эта проблема напрямую связана с производством подшипников, специальных смазок и систем 

смазки (например, с использованием масляного тумана), специальных систем стабилизации температуры. Но главным ограничивающим фактором является не только дефицит высокоточного оборудования, но и недостаточно высокая культура производства (подготовка особых сборщиков шпиндельных узлов, обладающих высочайшей квалификацией).

Обычно шпиндельные узлы изготавливают заводы - изготовители станков. Иная ситуация с электрошпинделями (или мотор-шпинделями). Их производство обычно осуществляется на специализированных предприятиях, но и в России сегодня производят их некоторые предприятия, такие как «Стан-Самара», Стерлитамакский станкозавод по лицензии фирмы Kessler (Германия). В CССР электрошпиндели на различных типах подшипников, в основном для высокоскоростного шлифования, а также шпиндели на воздушных опорах производил завод «МЗСП» (Москва). Сегодня этого завода нет, хотя его скомплектованное оборудование находится в МГТУ «СТАНКИН», и при желании производство может быть восстановлено. Шпиндель имеется на каждом станке, и производство их в широкой номенклатуре является необходимостью.

Для решения проблемы необходимо изучить вопрос о номенклатуре ведущих фирм, таких как Fisher (Швейцария), SKF (Швеция), Ibag (Швейцария) и др. Ранее ЭНИМС вел совместные работы с фирмой Ibag.

Другим видом критических комплектующих являются револьверные головки. Их производство в России существует, но они очень сильно отстали от потребностей современных станков. Образцом современных револьверных головок могут служить головки фирм MoriSeiki и Nakomura-Tome (Япония), Sauter (Германия), Duplomatic и Baruffaldi (Италия). Обязательной функцией современных револьверных головок является наличие возможности установки вращающегося инструмента в разных позициях (вдоль оси и поперек оси). Максимальное число инструментов достигает 24 позиций, при этом обеспечивается высокая точность и жесткость. Интересные конструкции револьверных головок

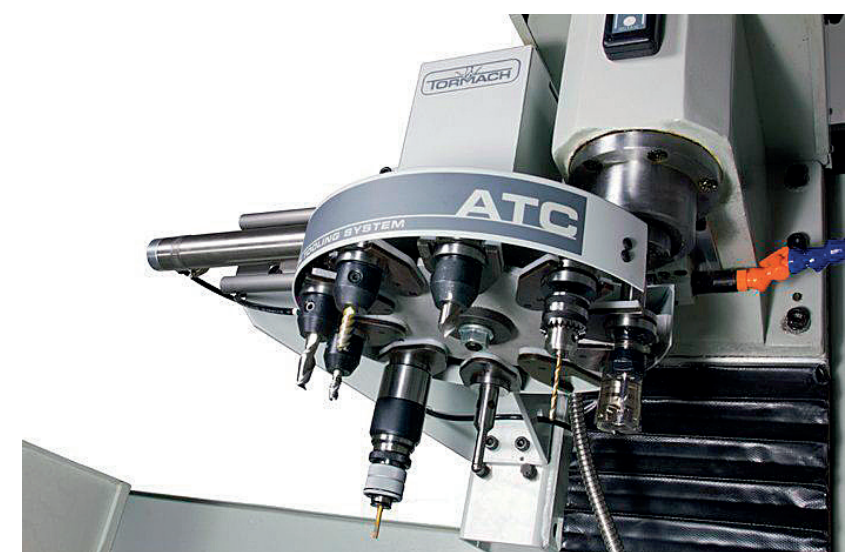

имеются у фирмы Nakomura-Tome. Некоторые револьверные головки имеют возможность занимать в пространстве любое положение, обеспечивая обработку деталей под любым углом.

\section{КОМПЛЕКТУЮЩИЕ, В ПРОИЗВОДСТВЕ КОТОРЫХ \\ В РОССИИ НЕТ НЕОБХОДИМОСТИ И КОТОРЫЕ МОЖНО И НУЖНО ПОКУПАТЬ НА ГЛОБАЛЬНОМ РЫНКЕ}

Комплектующие изделия, производство которых не требует мер государственной поддержки, как правило, произво-

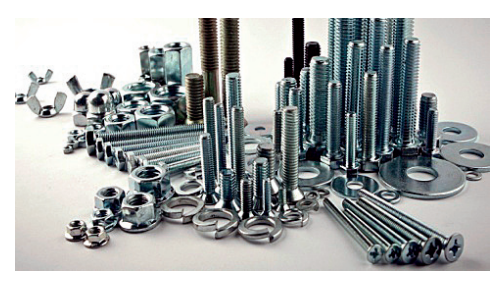
дятся в странах

Юго-Восточной Азии, на небольших частных предприятиях, иногда семейных. В то же время в этот список вошли и сложные изделия, которые применяются в станках не настолько часто, чтобы было рентабельно их производить в нашей стране.

К первому типу относятся устройства защиты направляющих, крепежные изделия, пластмассовые изделия, кнопки, ручки, фитинги, шланги и др., по типу изделий фирмы Parker, аппаратура местного освещения рабочих зон станков.

Ко второй группе относятся более сложные изделия, такие как шарнирные узлы для конструкций с параллельной кинематикой (триподов) по типу фирмы INA (Германия), устройства дробления стружки вне станка и ее брикетирования, станции переработки масел и СОЖ с частичным восстановлением, насосы, трубы и аппаратура для станков гидроабразивной обработки, гибридные разъемы для коммутации гидро-, пневмо-, электро- и электронных цепей и сигналов, кондиционеры рабочей среды (фильтры, теплообменники), вытяжки и пылеотсосы.

\section{ЗАКЛЮЧЕНИЕ}

Предложения Ассоциации «Станкоинструмент» основаны на опыте отечественного и иностранного станкостроения. Отдельные пункты могут меняться местами. Например, если будет построено специализированное предприятие для производства комплектующих, оно может, по примеру таких компаний, как Fanuk и Mazak (Япония), или Röhm (Германия), производить широкий спектр узлов. Такое предприятие могло бы выпускать направляющие качения (по образцу ТНК, Япония), токарные патроны, гидроприводы патронов, инструментальные патроны, поворотные патроны и другую оснастку (по образцу Röhm, Германия), шариковые винтовые 
передачи типа (по образцу SKF, Швеция) и другие изделия, требующие термоконстантных условий, высочайшей культуры производства, высокоточных станков и суперточных измерительных систем и приборов.

Опираясь на опыт стран ЕС и других высокоразвитых стран, необходимо экономическое стимулирование по освоению новых производств комплектующих изделий, а именно освобождение от налогов на прибыль, землю, имущество, транспортный налог не менее чем на 5 лет, а также субсидирование затрат на подготовку производства в размере не менее $50 \%$. Причем налог на прибыль является стимулирующим налогом: налог не изымается, если средства идут на создание новых рабочих мест, строительство новых производств, внедрение новой продукции, разработку и внедрение инноваций. В некоторых странах при использовании 50\% прибыли на цели, указанные выше, вторую половину оставляют предприятию, и оно может использовать ее по своему усмотрению.

Используя финансовые механизмы, обеспечивающие инвестиции для восстановления, создания и модернизации производств, необходимо выпускать на своей территории как можно больше комплектующих, чтобы снять критическую зависимость от высокоразвитых стран. Для обеспечения независимости от импортных поставок и технологической независимости, особенно в условиях жесточайших санкций, необходимо обеспечить создание и производство высокотехнологичных комплектующих изделий.

\section{ЛИТЕРАТУРА:}

1. Архивные данные Минстанкопрома СССР и Госкомстата РФ. - М., 1993. Выписка из отчета Госкомстата РФ о технологической и возрастной структуре парка металлообрабатывающего оборудования по машиностроительным отраслям, 1992 г.

2. Народное хозяйство СССР в 1990 г. (статистический ежегодник). - М.: Госкомстат СССР, изд. «Финансы и статистика», 1991.

\section{ПЕСКОВ Алексей Максимович - \\ вице-президент Ассоциации «Станкоинструмент»}

\section{ИВАХОВ Виктор Моисеевич -}

вице-президент Ассоциации «Станкоинструмент»

\section{ЮДЕНКОВ Николай Петрович -}

заместитель главного редактора журнала «СТАНКОИНСТРУМЕНТ»

\section{КНИГИ ИЗДАТЕЛЬСТВА «ТЕХНОСФЕРА»}

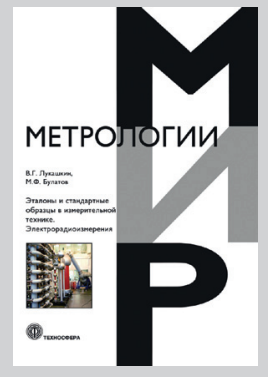

Цена 840 руб.
ЭТАЛОНЫ И СТАНДАРТНЫЕ ОБРАЗЦЫ В ИЗМЕРИТЕЛЬНОЙ ТЕХНИКЕ. ЭЛЕКТРОРАДИОИЗМЕРЕНИЯ

\author{
Лукашкин В.Г., Булатов М.Ф.
}

Издание осуществпено при финансовой поддержке Федерапьного агентства по печати и массовым коммуникациям в рамках Федерапьной цепевой программы «Культура России (2012-2018 годы)»

В книге рассмотрены общие вопросы метрологического обеспечения и единицы физических величин. Изложены основные задачи технических средств метрологического обеспечения в области электрорадиоизмерений. Даны оценки погрешности и неопределенности первичных и рабочих эталонов.

Книга может быть полезна студентам и аспирантам при выборе и обосновании эталонной базы в области электрорадиоизмерений, а также специалистам, занимающимся вопросами разработки, производства и оценки качества средств измерений, контроля и испытаний. 